\title{
語用論的ゲーム理論によるニセ情報発話分析 \\ A Pragmatic Game-Theoretic Analysis of False Information Speech
}

\section{陳 訪澤/甘 能清 澳門大学/華南師範大学}

\begin{abstract}
False information speech often appears in daily communications. Grice's cooperative principle cannot explain it. Leech's politeness principle and Brown \& Levinson's face theory also cannot completely explain it. The present study methods cannot deeply reveal the essence of false information speech. This paper studies false information speech by making use of game theory, especially the pragmatic game theory. False information speech was found to be a strategy dominant in verbal interaction between two sides of communication. The use of false information speech by speaker and hearer was also found to create Nash equilibrium in the game of Prisoner's Dilemma. Thus, this analysis helps to effectively explain why false information speech can maximize the individual payoff while damaging the collective payoff, and why it is used frequently by individual while being spurned by the group (society).
\end{abstract}

\section{Key Words}

False information speech, Pragmatic game theory, Dominant strategy, Game of Prisoner's Dilemma, Nash equilibrium

\section{要旨}

ニセ情報発話は日常のコミュニケーションにおいてよく現れるものである。ニセ情 報発話について、Grice の協調の原則はこれを解釈することができないし、Leech の丁 寧さの原則とBrown \& Levinson のメンツ理論もこれを全面的に解釈することはできな い。つまり現在の研究手段はニセ情報発話の本質を深く掘り下げることができない。 そこで、本研究はゲーム理論、とくに語用論的ゲーム理論を導入して分析した結果、 二セ情報発話はコミュニケーション双方の言葉のやりとりにおける支配戦略であり、 話し手と聞き手の発話に見られる囚人のジレンマゲームにおけるナッシュ均衡である。 これは、二セ情報発話は個人の利益を最大にするが集団の利益を損ない、個人には頻 繁に利用されるが集団や社会には拒否されるということをよく説明している。

キーワード:

二セ情報発話、語用論的ゲーム理論、支配戦略、囚人のジレンマゲーム、ナッシュ均衡 


\section{A Pragmatic Game-Theoretic Analysis of False Information Speech}

\section{CHEN Fangze / GAN Nengqing University of Macau / South China Normal University}

\section{Introduction}

Grice's cooperative principle requires people to observe "the maxim of quality" in speech communication and not to say what you believe to be false, that is, to say what is true. But in casual talk of the daily communications, that every word should be true may not be necessary. No matter which country's language is, there more or less exists the "non-truth" false information speech in the actual speech communication. For example:

(1) Not long after the liberation, the leader of municipal government, Lin Ran, convened some intellectuals to have a forum to propagandize the Communist Party's economic policy. Professor Xian Yu was also invited to the forum. Lin Ran's speech had not completed when Professor Xian Yu quietly left the meeting room. On seeing this, Wen Hua, a friend of Xian Yu's, followed him to go out.

Wen Hua: Xian Yu, aren't you going to leave?

Xian Yu: I am a teacher and I am not interested in such preach.

Lin Ran: (appearing at the door suddenly) Professor Xian Yu, you are leaving?

Xian Yu: Well, I am hurrying to give classes.

\section{(TV series Country) ${ }^{1}$}

(2) The strength of the South Korean football team obviously surpasses that of the Chinese football team. However, at every pre-match press conference, the South Korean coach is always saying: "The Chinese team is a team with great strength!"

From the above examples, we can see that neither Professor Xian Yu was really hurrying to give classes nor the South Korean coach truly believes that the Chinese team is a strong one. What they said is not "truth". These kinds of "non-truths" contain false, non-authentic information. We can call such utterances "false information speech". We believe that the speaker sends out false information speech to express certain implications. Why then do people violate the maxim of quality? Why do they deliver speech that contains non-authentic and false information? Grice's cooperative principle cannot explain them but Leech's politeness principle and Brown \& Levinson's face theory can to some extent compensate for the shortcoming of the cooperative principle, by explaining some "non-truth" false information

1 The TV series Country, run in June 2003, was directed by Zhou Yong and Bater. This conversation is quoted from He \& Zhang (2004). 
speech. However, not all the use of false information speech is out of politeness. Therefore, it is necessary to have a more in-depth discussion of false information speech.

\section{The literature review of false information speech}

Among the past studies in China, because of the difference of the study perspectives, the terms for false information speech are not the same. This paper adopts the concepts of truth and falsity of "information" in game theory. Speech which contains non-authentic and false information is termed as "false information speech"; while the speech which doesn't contain non-authentic and false information is termed as "true information speech". This overlaps some commonly used terms in previous studies, such as "deception" (referred to as DEC), "hypothesis", "falsehood" "lying", "lies", "speech false information" and so on, but it is distinct from them. The study of false information speech in China began from Qian (1987). Qian (1987) thinks that non-authentic information released and received in speech communication activities (spoken or written) is termed as "false information speech", and he also points out that false information speech is one of the ubiquitous means of communication. False information speech can be divided into "false information speech of interests" ${ }^{2}$ and "false information speech of function" ${ }^{3}$. Up till now, scholars have studied false information speech from various perspectives including ethics (Bok 1978, Habermas 1979, Wilson \& Sperber 2002), philosophy and psychology (Aiba 1988, Ma 1997), sociology (Barnes 1994), pragmatics (He \& Zhang 2004, Yang \& He 2007, Liu 2003, Zhang 2008), and rhetoric (Hu 1990a, 1990b, 1991a, 1991b, 2003, Fan 1992).

The ethical study of DEC is based on the perspective of ethics. From the perspective of ethics, DEC is spurned both in east and in west because false information speech is believed to be immoral (Ikuenobe 2002). The philosophical study of DEC mostly starts from the authentic

2 One knows himself pretty well the output information is wrong, but sends it out to the ignorant hearer so as to lead to the outcome that is not conducive to the hearer. That information belongs to the false information of harm; while if it leads to the outcome that is conducive to or at least is harmless to the hearer, it belongs to the false information of good.

3 Though one knows himself pretty well that the information he is going to send out is not true and that the two participants of the communication can find out that it is false, he still sends it out. Also, the receiving one doesn't mind that it is false or its harm and even has the feeling that false is better than true, and thus accepts it happily. Such kind of non-authentic information delivery which can have special effects and sends out under the restraint of the specific confirming background is called as functional false information. 
importance and the non-authentic harmfulness. For example, Bok (1978) thinks that even if the lies do not cause harm to a person, it is still harmful to the whole human beings. No matter ethical study or philosophical study, they all emphasize true information speech too much and insist on telling the truth, and they are apt to deny the existence of DEC. Therefore, it is inevitably one-sided and does not accord with reality.

The studies of DEC from the perspectives of psychology and forensic linguistics tend towards practical research, such as DEC detection study. Psychology focuses on studying the liar's mental process and its corresponding physical responses. The study of forensic linguistics suggests that we can analyze the language of interrogation and confession by using statement accuracy evaluation, authenticity supervision, scientific content analysis ( referred to SCNA), lexical diversity, so that we can identify inconsistencies in these languages, and tofind evidence of using deceptive language (Shuy 1988, Zhang \& He 2006). However, it seldom pays attention to language itself and the characteristics of false information speech itself.

The study of DEC from the perspective of sociology is broader because false information speech doesn't exist in a vacuum but commonly exists in every field of social life. Different fields of social life and different cultures have different evaluations of it. Moreover, different people have different evaluations of the same content of false information speech. Ma (2001) points out that the Japanese and Americans have differences about the judgment of lies. The study of DEC from the perspective of sociology, especially the DEC study of different social cultures, contributes to complementing and perfecting cross-cultural study. However, this kind of study fails to deeply reveal the whole process of using DEC as well as the psychological, the cognitive and other factors in this process. Furthermore, it lays particular stress on social and cultural factors rather than psychological and cognitive factors. Therefore, such kinds of study are not systematic and comprehensive enough (Zhang \& He 2006).

The study of DEC from the perspective of rhetoric is more commonly seen among domestic scholars (Hu 1990a, 1990b, 1991a, 1991b, 2003, Fan 1992). They mainly study the DEC use of all kinds of rhetoric means such as exaggeration, metaphor, etc. They also focus on how the false information speech which acts as figures of speech is being used and what effects they have, but they don't investigate into the whole process of the language activity of DEC.

All the studies of DEC above which are from different disciplinary perspectives are static studies of false information speech rather than dynamic studies. Therefore, the study of DEC from the perspective of pragmatics comes into being. He \& Zhang (2004) use adaptation theory to conduct fairly effective research on DEC, which made clear that in communication, 
the choice of language is influenced by the psychological world, the social world and the physical world. The so-called psychological world includes verbal communicators' psychological factors, such as personality, emotions, beliefs, aspirations, motivation .etc. The social world refers to social occasions, social environment, and the principles and guidelines to standardize communicators' speech act. The culture is an important related factor (Verschueren 1999:91-92, Zhang 2008:144). The physical world refers to the communicative actual time, place, object, etc, which points out that the speaker selects DEC in order to conform to both speaker's and hearer's psychological world, social world and physical world. However, why the speaker must conform is not made clear. Pan \& Bu (2008) use relevance theory to conduct a preliminary research on DEC's language strategy. From a cognitive point of view, it pointed out that relevance theory has strong explanatory power on pragmatic strategy of false information, but "it is only a general description of the relevancy assumption's effect on DEC's implementation strategy, and does not involve the further questions, such as how speakers conduct correct relevancy assumptions" (Pan \& Bu 2008:141).

Furthermore, there are some scholars who adopt the speech act theory to explain the phenomenon of false information speech. But just as He \& Zhang (2004) point out, such explanation would lead to the appearance of paradox. The speaker is performing an illocutionary act when he delivers false information speech. Searle's speech act theory points out that to successfully perform an illocutionary act, people must meet certain conditions, one of which is the sincerity condition. If one wants to send out false information speech successfully, he must perform the illocutionary act successfully. If he doesn't meet the sincerity condition, the false information speech as an illocutionary act cannot be successful. Therefore, if this speech act is successful at last and becomes an illocutionary act (i.e. the successful performance of false information speech), it means then the performance of a previous illocutionary act is successful. However, performing the illocutionary act of false information speech will never be successful because it cannot meet the sincerity condition of performing this speech act. That leads to the appearance of paradox. To settle this paradox, we should revise the rule that to perform an illocutionary act, people must meet the sincerity condition required by Searle's speech act theory.

Besides, in recent years, with the linguistics' turn toward economics as well as the economists' linguistics turning, the cross-linking studies of economics and linguistics emerge steadily. Yin \& Jiang (2005) have conducted an economic analysis of lying. They put forward the theories of "lying meets economic man's assumption", "lying obeys economic rationality" and "lying fits interest motivation". Yin \& Jiang (2005) provide a relatively new perspective for 
the study of false information speech, which still needs further improvement to make the study systematized.

Among the antecedent studies directed at false information speech, whether it is the study from the perspectives of ethics or of philosophy, or the study from the perspectives of psychology or of sociology, they are all limited to the static study of false information speech. Though the study from the perspective of pragmatics begins to pay attention to the dynamic study of false information speech, it cannot yet exactly reveal the essence of false information speech simply with the help of adaption theory or relevance theory. Therefore, this paper intends to use the related theories of game theory so as to have a systematic analysis on false information speech, hoping to dissect the essence of the use of false information speech.

\section{From game theory to pragmatic game theory}

\subsection{What is game theory?}

Games are one of the oldest social activities in human history. In China, the known strategic game act has been reflected in the story of Scripts and Scribes as early as more than 2000 years ago. Abroad, the "the marriage contract" discussed in the Talmud of ancient Babylon contains game acts. However, the systematic study of the game and making it a science----Game Theory dates back to mid-1940s to early 1950s. The American mathematician, Von Neumann and Oskar Morgenstern founded the modern game theory together in early $20^{\text {th }}$ century. After that, John Nash and other scholars made further development and improvement. Today's game theory has developed into a relatively complete discipline. Game Theory has been once translated into "Dui Ce Lun" (“對策論”), and now is more often translated into "Bo Yi Lun" (“博峦論”) in China, while it is translated into "You Xi Li Lun" (“遊戲理論”) in Taiwan.

In daily life, the word "game" can generally refer to all kinds of games, such as board games, poker, and all kinds of sport competitions and so on, but in game theory, "game" is strictly defined as the situation in which the behaviors of a completely rational individual or group have direct interaction with one another. Game theory is the theory of studying individual's or group's choices (that is, decision) under such situations and the results of those choices. We can borrow the point of view of Professor Robert Aumann who won the Nobel Economics Prize in 2005 because of the game theory----games are the strategically interactive decision-making processes. All games should include at least (but not limited to) the following three elements: 
- Players whose goal is to realize his own maximal benefit (a set of players) (player)

- Strategies or strategic spaces of action that players can choose (strategy)

- Payoff that players may get when a game is over (payoff)

Apart from those three elements, all players' information structure that affects the result of a game is also very important, especially the knowledge and information of competitor's characteristics and behaviors. Under the premise that other players don't change their current strategies, any player cannot get a higher payoff by changing his own strategies unilaterally. If this situation happens, it means the game has reached a "resolution", or has reached Nash equilibrium, which is the set of all players' optimal strategies or actions.

The mode of game theory can be described as five aspects, that is $\mathrm{G}=\{\mathrm{P}, \mathrm{A}, \mathrm{S}, \mathrm{I}, \mathrm{U}\} . \mathrm{P}$ (player) refers to players, that is, the participants of the game. It is also called "game party". A player's goal is to finally realize his own maximal benefit. A (action) is the set of every player's all possible strategies or actions. According to whether the set is definite or not, it can be divided into a definite game and infinite game. S (strategy) is the game process and the game order. It can be divided into static games and dynamic games. I (information) refers to game information. If all the players know clearly each one's benefit state, it is called a game of complete information; otherwise, it is called a game of incomplete information. $U$ (utilities) refers to the benefits that players get. It is the final goal of all players. According to the different situations of all participants' benefits, it can be divided into zero-sum game and variable-sum game. The mode of game theory has lots of typical cases. The most familiar one is the mode of Prisoner's Dilemma which is seen as one of the classic cases of Nash equilibrium.

Prisoner's Dilemma supposes that there are two thieves A and B who are caught by the police because of committing crimes of larceny and trespassing together. The police put them separately into two different rooms and interrogate them. For each suspect, the police offer the following policy. If one suspect confesses his crime and hands in the stolen goods, then their crime is proved and both of them are declared guilty. If another suspect also confesses his crime, then both are sentenced to eight years; while if another suspect doesn't confess his crime but denies, he will receive an additional punishment of two years (for the existing evidence has proved his guilt) and the one who has confessed can commute an 8-year prison sentence and be released at once because of his confession. If both of them deny, the police cannot declare their guilt of committing larceny for the lack of evidence, but the two suspects can be sentenced to one year by the police because for trespassing. The following chart is the payoff matrix of this game. 
The matrix of the game of Prisoner's Dilemma

\begin{tabular}{|c|c|c|}
\hline $\mathrm{A}$ & confess & deny \\
\hline confess & $-8,-8$ & $0,-10$ \\
\hline deny & $-10,0$ & $-1,-1$ \\
\hline
\end{tabular}

Obviously, they two will be sentenced to only one year if they conspire to deny together. However, because they are separated, both of them choose to confess at last. It is obvious that "confession" is the dominant strategy of either suspect and it is the equilibrium of dominant strategy. One typical characteristic of the mode of the game of Prisoner's Dilemma is that though confession can be the maximization of individual benefit, it results in the loss of the whole benefit of both.

As the mode of the game theory shows, almost all the decision-making matters can be regarded as games. The selection and application of language is also one kind of game.

\subsection{Language game theory}

The concept of language game can be traced back to the Austrian philosopher Wittgenstein's "language-game" theory. He first points out clearly the relationship between game theory and language. The contemporary outstanding philosopher and logician Hintikka absorbs the thinking essence of game theory as well as Wittgenstein's language-game theory and puts forward the language game theory in its true sense. He points out that the language game relating to a word is the activities concerning the word which are typical and can make the word attain its meaning. The two players who participate in the game can respectively be called "oneself" and "nature". The aim of "oneself" is to make the game end in a true matrix with an exemplification, while "nature", the competitor of "oneself" attempts to make the game end in a false matrix. The concept of Hintikka's language game is different from that of Wittgenstein for it has very specific definition. Just as Hintikka emphasizes, even from the point of view of pure mathematics, a language game is a true game and moreover a zero-sum game (Lin 2007). Wang (2001) thinks, "We can imagine that on the occasion which people's language acts can be regarded as a 'game', the meaning of the specific words can be considered to be determined by the equilibrium state of the game."

The language game theory shows that a game exists in the output of the language, especially the output of the words. Besides, there are also games in language use, especially in speech communication. 
The language output refers to activities in which language "attains" its meaning. The language use refers to activities in which the language "expresses" meaning. The former is the game equilibrium of "oneself" and "nature", while the latter can be either the game equilibrium of "oneself" and "nature", like the speaker's talking to himself, or can be the game equilibrium of "oneself" and "others", like dialogue (Tang 2000). In any communication, the communication between the two parties constitutes a game. In communication, the speaker is the player and his actual speech act is the result of language selection and his strategies; the result of communication is the result of the game, that is, payoff. Therefore, it is obvious that there is a game existing in the use of language.

\subsection{Pragmatic game theory}

Pragmatics is the study of the relationship between language and its users. The use of language cannot be separated from communication. Pragmatics has a close relationship with interpersonal communication.

Qian (2005) put forward the concept of "the pragmatic game theory" in early years. He points out that pragmatic game theory develops from game theory and it has the following extension, that is:

(1) Language communication is a kind of decision-making and it is the use of language strategies. The use of language, especially dialogue, is the process in which the speaker and the hearer interact and select strategies constantly. The word "communicate" in the "language communication" is a vivid reflection of the state in which the speaker and the hearer interact and compete in the language game.

(2) The cooperation in language communication doesn't need to be a rule. In reality, language communication demonstrates competition, cooperation and conflict according to the different results. Whether the conversation in communication is cooperative or non-cooperative primarily depends on whether the players of the game, that is, the speaker and the hearer can gain a payoff. Only when both of them can gain a payoff does the conversation become a hopeful one and then the conversation can be successful.

(3) The outcome of both players' conversation in language communication is the result of their decision selection and compromise. Both the speaker and the hearer have a set of optimal selection which is controlled by the outcome. This is the dominant strategy ${ }^{4}$ of the language game. In pragmatic game theory, both communication participants' language decision selection

4 The dominant strategy is a term used in game theory referring to one's own present strategies as optimum; regardless of whatever strategies the other one involved in the game chooses. 
and cooperative decisions (for example whether to deliver false information speech or not. etc.) are under the control of the dominant strategy.

Qian (2005) mentions, "From what we have heard and the on-line key words, we have known that some western scholars have applied game theory to the study of pragmatics. It is natural." Undoubtedly, the study of the pragmatic game theory has been developed greatly in western countries. For example, the book Game Theory and Pragmatics has been published by Palgrave Macmillan in 2006. The book's literature comes from the academic meeting of "Game and Decision in Pragmatics" which was held in Berlin's General Linguistics Center in October, 2003. The editor is the famous scholar of two-way optimization theory in the continent of Europe at present. Among the authors, there are many authorities of linguistics.

The existing research results show that the pragmatics game theory mainly studies the problem of optimization of speech strategies in communication. In this sense, the pragmatic game theory can be seen as two-way optimization theory. Below we try to use the pragmatic game theory to analyze the false information speech acts so as to see through the essence of the false information speech acts.

\section{Analysis of false information speech from the perspective of game theory}

\subsection{Definition and classification of false information speech}

False information speech in communication involves the speaker $(\mathrm{S})$ and the hearer $(\mathrm{H})$. All the previous definitions are simply from the perspective of $\mathrm{S}$, while ignoring the perspective of $\mathrm{H}$. Integrating $\mathrm{S}$ and $\mathrm{H}$ to analyze false information speech, we have the following four situations: (A) SH all believe it to be true; (B) SH all believe it to be false; (C) $\mathrm{S}$ believes it to be true while $\mathrm{H}$ believes it to be false; (D) $\mathrm{S}$ believes it to be false while $\mathrm{H}$ believes it to be true. Among them, (A) doesn't contain false information; (C) belongs to misunderstanding. Therefore, only (B) and (D) have false information speech.

On the other hand, the speaker's speech includes honesty and authenticity. Ma (2001) points out that the speech's honesty (two sides: sincerity and hypocrisy) and authenticity (two sides: true and false) are two different things. The former one talks about the speaking attitude while the latter one talks about the speaking content. Sincerity indicates that the speaker makes a description which accords with his cognition; hypocrisy refers to the speaker purposely making an adverse description though he knows whether it is true or false clearly. True and false have something to do with statement. When the statement is compared to the objective world, if its truth-value is in conformity, then it is true; if its truth-value is out of conformity, then it is false. This is showed as the following diagram form: 


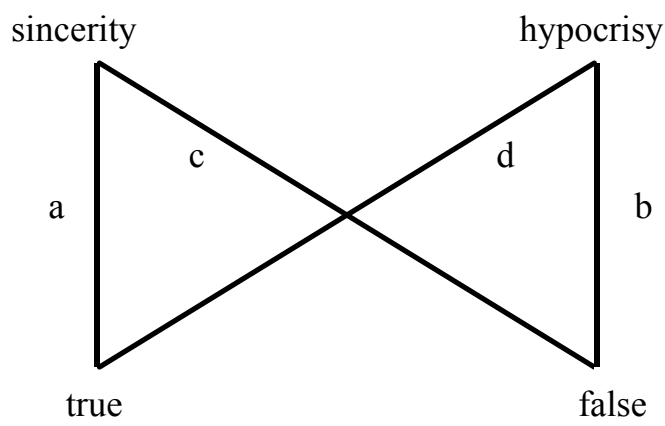

Therefore, from the perspective of the speaker, false information speech can be divided into false information speech of attitude and false information speech of content. False information speech refers to the speech containing information of hypocritical attitude or false content which is sent out and received in speech communication activities ${ }^{5}$. To sum up, false information speech can be further divided into 6 situations. As the following chart shows:

The classification of false information speech

\begin{tabular}{|c|c|c|c|}
\hline \multirow{2}{*}{} & \multicolumn{2}{|c|}{ speaker } & \multirow{2}{*}{ hearer } \\
\cline { 2 - 3 } & honesty & authenticity & true $($ accept $)$ \\
\hline $\mathrm{a}$ & sincerity & false & false $($ refuse $)$ \\
\hline $\mathrm{b}$ & sincerity & false & true $($ accept $)$ \\
\hline $\mathrm{c}$ & hypocrisy & true $\rightarrow$ false & false $($ refuse $)$ \\
\hline $\mathrm{d}$ & hypocrisy & true $\rightarrow$ false & true $($ accept $)$ \\
\hline $\mathrm{e}$ & hypocrisy & false $\rightarrow$ true & false $($ refuse $)$ \\
\hline $\mathrm{f}$ & hypocrisy & false $\rightarrow$ true & \\
\hline
\end{tabular}

\subsection{Analysis of false information speech from the perspective of Prisoner's Dilemma}

Game theory supposes that rational people completely fit the characteristics of the speaker and the hearer in communication. If the speaker and the hearer are non-rational people, they will have incoherent talk and their speech will fail to express its meaning, and thus the communication cannot go on. Rational people will seek the maximum benefit in communication and the two communication participants will pursue the maximum success of communication. From the perspective of the speaker, sending out false information speech

5 Refer to Qian (1987)'s definition of false information speech. 
can't be action on impulse. It is the absolutely rational speech act of an individual under the situations of constraint conditions and risk preference. Whether to send out false information speech definitely depends on whether the benefit can be maximized or not (including getting the maximum benefit and receiving the minimum punishment). Similarly, from the perspective of the hearer, whether to receive false information speech also depends on whether the benefit can be maximized or not. In this way, the game acts of false information speech between the speaker and the hearer become a game of communication.

Let's go back to see the conversation (1) at beginning. The communication may lead to at least two situations: Lin Ran reacts to consider Xian Yu's speech as "true" or "false".

(1') If Lin Ran considers as "true":

Xian Yu: Well, I am hurrying to give classes.

Lin Ran: Really? Please take care.

(1") If Lin Ran considers as "false":

Xian Yu: Well, I am hurrying to give classes.

Lin Ran: Oh no, it is in recess now.

If the conversation can be regarded as a complete game of communication (G), $G$ may contain several sub games. That started from Xian Yu's speech "Well, I am hurrying to give classes" can form a sub game of G.

Given:

$\mathrm{p} 1=$ Intention 1 of $\mathrm{S}=$ Indirect meaning of the speech= to find an excuse for leaving= "I am not interested in such forum. I am going to leave"

p2=Intention 2 of $S=$ Surface meaning of the $\operatorname{speech=}$ to explain the reason= "I am hurrying to give classes. So I cannot attend the meeting"

In the sub game between Xian Yu and Lin Ran said above, there may be roughly two strategies while Lin Ran $(\mathrm{H})$ interprets Xian $\mathrm{Yu}(\mathrm{S})$ 's speech. One is to consider the speech as its surface meaning. That is to accept the information speech as "truth" and to consider that $\mathrm{S}$ is explaining the reason and delivering p2. Another is to consider the speech as its indirect meaning other than the surface meaning. That is to refuse to accept the information speech as "truth" and to consider that $\mathrm{S}$ is finding an excuse and delivering $\mathrm{p} 1$. The following chart shows the matrix of the game. 
False information speech: the matrix of game

\begin{tabular}{|c|c|c|}
\hline H=Lin Ran & refuse & accept \\
\hline $\mathrm{p} 1=$ Xian $\mathrm{Yu}$ & $\mathrm{p} 1, \mathrm{p} 1$ & $\mathrm{p} 1, \mathrm{p} 2$ \\
\hline $\mathrm{p} 2=$ Sending out false information speech & $\mathrm{p} 2, \mathrm{p} 1$ & $\mathrm{p} 2, \mathrm{p} 2$ \\
\hline
\end{tabular}

According to the common explanation of the game mode, there are two equilibriums (p1, p1) and (p2, p2) in this game mode: $\mathrm{H}$ refuses while $\mathrm{S}$ sends out false information speech and $\mathrm{H}$ accepts while $\mathrm{S}$ sends out true information speech. Obviously it is not the real aspect of the communication in false information speech. Actually in this game, Xian $\mathrm{Yu}$ is $\mathrm{S}$ and his benefit of sending out false information speech is greater than that of sending out true information speech. As to Lin Ran, he is $\mathrm{H}$ and his benefit of refusing false information speech is greater than that of receiving it. But that may greatly reduce the benefit of whole speech communication. In other words, both side of the speech in the game may take the strategy of noncooperation to realize the maximization of own payoff. This makes no difference with the typical feature of "the game of Prisoner's Dilemma". Therefore, we can use this game mode to explain the features of the false information speech game. Based on the payoff of various combinations of strategy in the mode of the game of Prisoner's Dilemma, the matrix of the game of Prisoner's Dilemma regarding false information speech can be shown as follows.

False information speech: the matrix of the game of Prisoner's Dilemma

\begin{tabular}{|c|c|c|}
\hline H=Lin Ran & $\begin{array}{c}\text { refuse } \\
\text { (noncooperation) }\end{array}$ & $\begin{array}{c}\text { accept } \\
\text { (cooperation) }\end{array}$ \\
\hline $\begin{array}{c}\mathrm{p} 1=\text { Sending out false information speech } \\
\text { (noncooperation) }\end{array}$ & 1,1 & 2,0 \\
\hline $\begin{array}{c}\mathrm{p} 2=\text { Sending out true information speech } \\
\text { (cooperation) }\end{array}$ & 0,2 & 3,3 \\
\hline
\end{tabular}

In this game, Xian Yu, the speaker was in a dilemma that he doesn't know which strategy Lin Ran would take. On account of the strategy of dominant equilibrium in the risk, he took the dominant strategy of "noncooperation" which would benefit him, sending out false information speech "I am hurrying to give classes". Based on the hearer's well-meaning 
principle $^{6}$, Lin Ran, the hearer mostly would take the strategy of cooperation in a game in order to maximize his own payoff such as conversation (1'). Thus the payoff of Xian Yu is increased and that of Lin Ran is reduced. The game does not reach the Nash equilibrium and may continue afterwards. Once Lin Ran understands that Xian $\mathrm{Yu}$ has sent out false information speech from the beginning in some contest, he may also take the dominant strategy of "noncooperation" such as conversation (1"). Thus the game would reach the Nash equilibrium (noncooperation, noncooperation). At least, the mode of the game of Prisoner's Dilemma regarding false information speech tells:

(A) False information speech can tentatively increase the hearer's payoff, but the whole payoff of both sides has been reduced rather than increased. It just explained that false information speech or telling lies could bring the benefit of individual, but they would harm to the social benefit. This is the reason why false information speech is unpopular and even spurned by people.

(B) False information speech begins from the strategy of noncooperation and finally makes the whole game to be the aspect of Nash equilibrium with the result of \{noncooperation, noncooperation $\}$. This is the reason why telling lies may get benefit at first time and will harm oneself at second time or third time. False information speech is finally hard to maximize one's own payoff.

\section{Conclusion}

In conclusion, we believe that the act of false information speech is the process of game of Prisoner's Dilemma between the speaker and the hearer. Sending out false information speech can maximize the speaker's benefit. It is the dominant strategy of the speaker. The reason why the false information speech appears is that it constitutes equilibrium of game of Prisoner's Dilemma in speech between the speaker and hearer.

Of course, we cannot deny that by using game theory, we reveal the essence of using false information speech, but the use of language is not static and there is difference in the specific game process of different language's false information speech. Therefore, it is necessary to have a further study on the specific language use. As for this, we will have another paper to have the further discussion.

6 Hearer $(\mathrm{H})$ believes speaker (S). In H's belief, if $\mathrm{H}$ cannot prove that speaker's proposition is "false", $\mathrm{H}$ should accept it. 


\section{References}

Aiba Hitoshi. Psychology of Lies. (Guan Dezhang, Li Jizhao translation.) (1988) Shenyang: Liaoning University Press.

Anton Benz, Gerhard Jäger, Robert van Rooij. (2005) Game Theory and Pragmatics. New York: Palgrave Macmillan.

Barnes, J. (1994) A Pack of Lies. Cambridge: Cambridge University Press.

Bok, S. (1978) Lying: Moral Choice in Public and Private Life. New York: Vintage Books.

Cao Yue. (2009) A Cognitive-pragmatic Approach to Lies in Verbal Communication. Journal of Hebei Polytechnic University (Social Science Edition), (2): 148-151.

Dong Zhiqiang. (2009) Ignorance of the Game: the Wisdom of Survival under Limited Information. Beijing: China Machine Press.

Fan Jun, Zheng Zhijun. (2007) Game in Translating: Foreignization and Domestication. Journal of Yibin University, (10): 97-100.

Fan Zhi. (1992) Modifying, Modification-head Structure and Deception. Rhetoric study, (1): 15-16.

Habermas, J. (1979) Communication and the Evolution of Society. London: Heinemann.

He Ziran, Zhang Shuling. (2004) Deception as a Pragmatic Strategy: An Adaptation-based Approach. Journal of Foreign Languages, (6): 25-31.

Hu Fanzhu. (1990a) The Connection among Language, Literature and Culture: Rhetoric and Philosophical Extracts from Qian Zhongshu Part 1. Rhetoric study, (2): 19-21.

Hu Fanzhu. (1990b) True Statement, False Statement, Factual Statement. Journal of Xuzhou Normal College (Social Science Edition), (1): 138-143.

Hu Fanzhu. (1991a) Getting Interested, Coherent Structure and Deception. Rhetoric study, (2): 9-11.

Hu Fanzhu. (1991b) An Analysis of Separated Lies. Rhetoric study, (4): 17-18.

Hu Fanzhu. (2003) From "Rhetoric Technique" to "Speech Act": A Primary Study on the Pragmatic Turn of Rhetoric Research in China. Rhetoric study, (1): 2-5.

Ikuenobe, P. (2002) The Meta-ethical issue of the nature of lying: Implications for moral education. Studies in Philosophy and Education. (21): 37-63.

James D. Miller, Game Theory at Work. (Li Shaorong translation.) (2006) Beijing: China Financial \& Economic Publishing House.

Li Yuansheng. (2007) The Study of False Information Speech as Pragmatic Strategy in Chinese. Journal of Mudanjiang University, (6): 43-45.

Lin Huaping. (2007) Game Theory of Translation Studies. Crazy English (Teachers), (9): $55-63$. 
Liu Dawei. (2003) Recursive Structure of Fictitious Speech act: Novel, Lies and Talk on Internet. Rhetoric study, (1): 5-8+12.

Luo Yunfeng. (2007) Game Theory Tutorial. Beijing: Tsinghua University Press.

Ma Hongwei. (1997) How to Prevent to be Deceived: Analyzing the Way of Deception and the Psychological Features. Taipei: New Rain Publishing House.

Ma Qinghua. (2001) The Analysis of Lies in Semantic Understanding. Rhetoric study, (6): 5-6.

Miyoshi Junichiro. (2004) New Language Research in making use of the Game Theory. Gekkan Gengo, (12): 54-61.

Murai Junichiro. (2005) Factors of Determining Deception Cognition of Speech Content. Kyoto: Kitaohji Shobo.

Pan Xiaohui, Bu Xiaowei. (2008) Deception under the Perspective of Relevance. Science \& Technology Information, (4): 140-141.

Pan Tianqun. (2008) Action Conversation in Games and Changing of Epistemic States. Journal of Zhejiang University (Humanities and Social Science Edition), (5): 13-17.

Qi Luxia. (1992) A Study on Prototype Theory: A Contrastive Research on English Lie and Chinese Sahuang. English-learning Psychology of Chinese Student. (Gui Shichun, Ed.) Changsha: Hunan Educational Publishing House.

Qian Guanlian. (2005) Language: Mankind's Last Home - the Philosophy of Basic Human Existence and Pragmatics. Beijing: The Commercial Press.

Qian Guanlian. (1987) Speech Function of False Information - and on Saving Grice's "Cooperative Principle". Journal of Foreign Languages, (5): 19-23.

Robert Van Rooy. (2004) Signaling Games Select Horn Strategies. Linguistics and Philosophy, (27): 493-527.

Shuy, R. W. (1998) The Language of Confession, Interrogation, and Deception. California: Sage Publications.

Tang Xiaojia. (2001) Linguistic Game Theory and Scientific Game Theory. Philosophical Trends, (5): 28-30.

Tang Xiaojia. (2000) An Analysis of Hintikka's Linguistic Game Theory. Journal of Southwest China Normal University (Philosophy \& Social Sciences Edition), (7): 39-44.

Verschueren, J. (1999) Understanding Pragmatics. Beijing: Foreign Language Teaching and Research Press.

Wang Bin. (2004) Translation and Game. Journal of University of Shanghai for Science and Technology (Social Science Edition), (2): 25-29.

Wang Dingding. (2001) Toward an Economics of Language. Sociological Studies, (6): 87-95. Wang Hong. (2002) On False Information. Shandong Foreign Language Teaching Journal. (2): 15-18. 
Wilson, D. \& D. Sperber. (2002) Truthfulness and relevance. Mind 111: 583-632. http://cogprints.org/2226/1/truthfulness.htm.

Wu Bingzhang. (2008) A Review on Game Theory and Pragmatics. Modern Foreign Languages, (2): 102-104.

Wu Bingzhang. (2009) Communicational Game Theory: A Kind of Theoretical Frame of Cognitive Pragmatics. PhD Dissertation of Henan University.

Xiang Mingyou. (2007) New progress in Pragmatic Research. Foreign Language in China, (2): 23-28.

Xiang Mingyou, Xia Dengshan. (2011) A Review of Game Pragmatics. Shandong Foreign Language Teaching Journal, (4): 15-20.

Xin Ju. (2003) On the Pragmatic Value of Lie. Journal of Shanxi Teachers University (Social Science Edition), (3): 126-128.

Yang Xiaorong, He Minglie. (2007) A Pragmatic Study of "Lies". Journal of Sichuan International Studies University, (5): 78-81.

Ying Jie. (2003) The "Linguistic Turn" and Its Significance. Social Sciences in China, (3): 53-63.

Ying Lei, Jiang Qifang. (2005) The Economic Analysis of Lying. Co-Operative Economy \& Science, (4): 63-64.

Zhang Fuguo. (2008) Pragmatic Analysis of White Lie and Its Perlocutionary Act. Journal of Zhaotong Teacher's College, (4): 28-30.

Zhang Jingtian. (2011) Game Pragmatics. Journal of Language and Literature, (10): 1-4. Zhang Liping, Ying Xuefeng. (2006) The Elements of Lie and Pragmatic. Journal of Inner Mongolia Agricultural University (Social Science Edition), (1): 285-286.

Zhang Shuling. (2008) The Operating Mechanism and Pragmatic Cause of Deception. Journal of South China Normal University (Social Science Edition), (2): 142-144.

Zhang Shuling, He Ziran. (2006) A Review of Deceptive Studies. Modern Foreign Languages, (1): 37-43. 